\title{
Emergency Medical Services (EMS) Calls During COVID-19: Early Lessons Learned for Systems Planning (A Narrative Review)
}

\author{
Alaa Al Amiry (D) \\ Brian J Maguire (iD) 2,3 \\ 'Department of Clinical Studies, College \\ of Pharmacy and Health Sciences, Ajman \\ University, Ajman, United Arab Emirates; \\ ${ }^{2}$ Leidos (Research Laboratory), Groton, \\ CT, USA; ${ }^{3}$ Central Queensland \\ University in Australia, Rockhampton, \\ Queensland, Australia
}

Background: Over the course of the COVID-19 progress, reports from many locations around the world indicated major increases in EMS call volume, which imposed great pressure on EMS dispatch centers (EMSDC) globally. No studies yet have been done to examine this phenomenon.

Objective: This paper examines the interrelated effects of the unprecedented global increase of EMS call, the effect of the COVID-19 crisis on responding to non-COVID-19 emergencies, and the concurrent effects of having overwhelmed dispatch centers. It tries to explain the current evidence of the bottleneck of EMS calls during the early phase of the worldwide pandemic.

Eligibility Criteria: We examine the numbers of EMS calls internationally between March and June 2020, derived from published literature and news media. Only articles in English were selected, with certain keywords related to EMS calls, ambulance delay, stroke and cardiac arrest.

Source of Evidence: Google Scholar was the main searching source.

Results: After applying the selection criteria, a total of 29 citations were chosen, and a pattern of knowledge resulted in the emergence of five themes: EMS calls during COVID-19, Reduced EMS operator response time, Ambulance response delays, Collateral mortality and morbidity among non-COVID-19 cases, and Total ambulance call time.

Conclusion: Over the course of COVID-19 progress, there was a global phenomenon of exponential increases in EMS calls, which is expected to impose a great pressure on EMS dispatch centers. Several factors contributing to the bottleneck of EMS calls are identified and explained.

Keywords: EMS calls, COVID-19, ambulance response time, RT, pandemic response, EMS access, ambulance delay

\section{Plain Language Summary}

During COVID-19 peak in 2020, EMS calls have surged unprecedently internationally, causing global disruption in EMS dispatch centers' services and significant delays in emergency response worldwide. We examined the bottleneck phenomenon that resulted in the disruption of EMS calls in different countries, and found three main factors:

- EMS-related factors

- Social-related factors

- Patient-related factors

For better understanding, we also explained each factor based on the available literature. Interestingly, we discovered a pattern of knowledge resulted in the emergence of five themes:
Correspondence: Alaa Al Amiry

Email a.alamiry@ajman.ac.ae 
EMS calls during COVID-19, Reduced EMS operator response time, Ambulance response delays, Collateral mortality and morbidity among non-COVID-19 cases, and Total ambulance call time.

We believe that by understanding these factors and their collateral impact on EMS calls, we can implement better crises and disaster response plans. This is an informative paper to EMS decision makers worldwide.

\section{Introduction}

Emergency medical services (EMS) play a major role in disaster operations, including responding to pandemics. ${ }^{1-3}$ EMS personnel role as first responders to biological disasters is well documented. ${ }^{4}$

Over the course of the COVID-19 progress, reports from many locations indicated major increases in EMS call volume. For example, in New York City (NYC) alone, EMS call volume rose from an usual daily high of 4000 calls to over 7000 calls. ${ }^{5,6}$ These dramatic increases in call volume can be expected to impose great pressure on EMS dispatch centers (EMSDC).

The optimal time-to-response (TTR) of 10-seconds established by European members, ${ }^{7}$ is at the core of EMS service to remain timely accessible. Becoming overloaded with calls is considered a major risk to EMS services, because any disruption to its primary goal of being timely will dramatically affect its contribution to the chain of survival. ${ }^{8}$

In order to determine COVID-19 global impact on EMS call volume and chain of survival, this study examines the number of EMS calls internationally, and describes collateral effects of increasing call volume on dispatch centers and community health, between March and June 2020. Up to author's knowledge, no studies have been done yet to examine this phenomenon and try to explain it.

This paper provides a global perspective on the pattern of EMS access by the public during COVID-19. This work aims to inform EMS managers and policymakers and to create a resource to aid in prospective management of this and future crises. Due to the nature of the matter in hand, authors believe that a narrative review would be best to synthesise conclusions and draw valuable, timeless lessons from the bottleneck affecting the EMS dispatch centers worldwide during such crises.

\section{Methods}

\section{Protocol}

Our methodology follows the PRISMA scoping reviews extension protocol. ${ }^{9}$ Appendix A shows which items were applied and which were not.

\section{Eligibility Criteria, Information Source and Study Selection}

Both Google and Google Scholar websites were searched for the following keywords among published scientific articles, pre-prints and news in the general media:

- EMS calls COVID-19

- Emergency calls COVID-19

- Ambulance calls COVID-19

- 911 calls COVID-19

- Stroke COVID-19

- Cardiac arrest COVID-19

- Heart attack COVID-19

- Ambulance delay COVID-19

Full-text citations in English were chosen, covering incidents between March and June 2020. Articles beyond this time period were excluded. This period of time was chosen as the first peak of COVID-19 pandemic.

\section{Charting the Data and Synthesizing Results}

Each article was read thoroughly to look for keywords and incidents supporting the study's aims. As patterns of knowledge were found, five themes have emerged:

- EMS calls during COVID-19, ${ }^{7,8,10-19}$

- Reduced EMS operator response time, ${ }^{7}$

- Ambulance response delays, ${ }^{14,20,21}$

- Collateral mortality and morbidity among nonCOVID-19 cases, ${ }^{14,17,19,22-29,31}$ and

- Total ambulance call time. ${ }^{17,29,33-35}$

\section{Results}

\section{Literature Search}

The selection process resulted in a total of 29 articles, ${ }^{7,8,10-35}$ in which 25 included either "COVID-19" or "coronavirus" in their titles, ( $n=20$ and 5 respectively), and four citations, in which COVID-19 was within the body. Most of the citations $(\mathrm{n}=18)$ included keywords "ambulance", "emergency", "EMS", and/or "paramedics" either in their titles or bodies, two citations involved "EMS calls" or "calls" within their bodies, two citations included "delay" in their titles, four articles included "cardiac arrest", "MI", or "heart attack" either in their titles or in their bodies, and six citations included "Stroke" in their titles. 


\section{EMS Calls During COVID-19}

EMS calls can play a major role in predicting the epicenter, clusters and progression of epidemics. ${ }^{10}$ In fact, the number and type of EMS calls are valid key indicators to predict many health-related conditions in a society. One study finds that daily COVID-19 EMS calls have the strongest correlation with the anticipated use of ICU beds, which can be utilized as an effective prediction tool for a possible second pandemic wave. ${ }^{11}$ Table 1 illustrates the changes in EMS calls in different geographical regions.

Even in the early days of the pandemic, the number of EMS calls began increasing in an unprecedented manner in many locations around the globe. For example, the number of EMS calls to the national EMSDCs in Israel

Table I EMS Call Volume Increases, Operator Time and Ambulance Response Times, During the Peak of Pandemic by City and Country, March to June 2020

\begin{tabular}{|c|c|c|c|}
\hline City/Country & $\begin{array}{l}\text { EMS Call } \\
\text { Volume } \\
\text { Increase }\end{array}$ & $\begin{array}{l}\text { Operator } \\
\text { TTR }\end{array}$ & $\begin{array}{l}\text { Ambulance } \\
\text { Response } \\
\text { Times }\end{array}$ \\
\hline Israel & $1900 \%$ & & \\
\hline $\begin{array}{l}\text { Copenhagen, } \\
\text { Denmark }\end{array}$ & $24 \%$ & $\begin{array}{l}500 \% \\
\text { increase in } \\
\text { TTR }\end{array}$ & \\
\hline $\begin{array}{l}\text { Manhattan, } \\
\text { New York City, } \\
\text { USA }\end{array}$ & $50 \%$ & & $46 \%$ increase \\
\hline Tijuana, Mexico & $\begin{array}{l}67 \% \text { (Urgent } \\
\text { cases) }\end{array}$ & & $25 \%$ increase \\
\hline $\begin{array}{l}\text { Northern } \\
\text { regions of Italy }\end{array}$ & $440 \%$ & & Up to one-hour \\
\hline Emilia Est, Italy & Three-fold & & \\
\hline Lombardia, Italy & Five-fold & & Up to one-hour \\
\hline $\begin{array}{l}\text { Lausanne, } \\
\text { France }\end{array}$ & $212.5 \%$ & & \\
\hline $\begin{array}{l}\text { Greater Paris, } \\
\text { France }\end{array}$ & $225 \%$ & & \\
\hline Catalonia, Spain & $330 \%$ & & \\
\hline $\begin{array}{l}\text { Bronx, NYC, } \\
\text { USA }\end{array}$ & & & $70 \%$ increase \\
\hline India & & & Up to 12 hours \\
\hline $\begin{array}{l}\text { Southern } \\
\text { Europe }\end{array}$ & & & $\begin{array}{l}30 \text { minutes } \\
\text { increase }\end{array}$ \\
\hline
\end{tabular}

increased $1900 \%$ during the first three months of $2020 .{ }^{12}$ EMS calls increased by $24 \%$ in Copenhagen, Denmark, ${ }^{7}$ and in NYC, the daily number of EMS calls increased more than $50 \%$ compared to pre-COVID-19 highs. ${ }^{13}$ While in Tijuana, Mexico, despite a drop in non-urgent calls, the proportion of urgent cases soared to $11.2 \%$ of total calls compared to a normal level of only $6.7 \%$ of all EMS calls. ${ }^{14}$ This influx of urgent calls may be influenced by a combination of panic and misinformation associated with COVID-19. ${ }^{15}$

Several studies conducted in different regions in Italy documented the increased surge of EMS calls. For instance, three days after the discovery of Italy's first COVID-19 case, the call volume to Emilia Est Dispatch Center increased three-fold. ${ }^{15}$ Meanwhile, in the northern regions of Italy, a sudden and sustained influx of EMS calls of $440 \%$ of normal levels was documented in the first five weeks of COVID-19 outbreak. ${ }^{16}$ The worst was in Lombardia, which was dubbed COVID-19 Ground Zero in Europe, where EMS calls swelled five times more than its EMSDC baseline. ${ }^{17}$

In Greater Paris, the number of daily EMS calls increased from 2000 to $6500 .{ }^{18}$ In Catalonia, Spain, EMS calls increased by $330 \%$ during the month of March, 2020, with unprecedented numbers reaching 40,000 EMS calls during three pandemic peak days. ${ }^{19}$ Tangentially, in Lausanne, France, non-emergency calls to a COVID-19dedicated "help line" received 2500 calls per day compared to 800 calls to their regular dispatch center line. ${ }^{8}$

\section{Reduced EMS Operator Response Times} This rapid increase of EMS calls can strain the EMS system's capacity and comes with potentially dramatic community health effects. Due to increased demand on EMSDCs, the time required to answer EMS calls by EMSDC significantly increased.

The overwhelmed EMSDCs of Copenhagen prompted an unprecedented prolonged queue to answer EMS calls. Call times increased to 12 minutes (mean time), compared to around two minutes in the pre-COVID-19 era, with some calls having a two-hour wait time. ${ }^{7}$ This can be considered as an indirect indicator of delayed dispatch of ambulances, keeping in mind the optimal TTR of 10 seconds.

\section{Ambulance Response Delays}

In Tijuana, Mexico, the response time (RT) of ambulances to arrive at the scene extended from 16.4 minutes in 2019 to 20.5 minutes during COVID-19 peak. ${ }^{14}$ This RT delay 
was also evident in NYC, where, in Manhattan and the Bronx, the average RT to life-threatening medical cases rose from 6.5 minutes pre-COVID to 9.5 minutes and 11 minutes, respectively. ${ }^{14}$ This was also observed in India. According to local news reports, extensive delays of 12 hours and more were frequent in several Indian states, rising morbidity and mortality. ${ }^{20,21}$

\section{Call Volume and Collateral Mortality for Non-COVID-I 9 Cases}

Recent literature identifies that the non-COVID-19 emergency cases most affected by the pandemic are stroke and cardiac arrest (Table 2). Since the pandemic onset, a global drop in the number of patients seeking medical care for these emergency conditions has been documented, ${ }^{22}$ suggesting a disruptive effect of COVID-19 to the chain of survival. For example, a survey conducted in the USA during April 2020 found an "alarming trend" for calling EMS. Evidence from a National Association of Emergency Medical Technicians survey shows an overall reduction in EMS responses by 34\%. EMS calls in Texas, dispatched to stroke and cardiac arrest have declined by $36 \%$ and $42 \%$, respectively. ${ }^{23}$ Similarly, dispatched ambulances to stroke-related calls has dropped by $20 \%$ and $29 \%$ in Chicago and New Jersey, respectively. ${ }^{24,25}$

Stroke admissions in Southern Europe have dropped as well by $25 \%$, and the number of EMS calls dispatched to stroke cases decreased, with a 30-minute delay in $\mathrm{RT}^{26}$ In
Catalonia, activation of stroke codes in a major stroke center dropped by $18 \%$ during the lockdown of the region. ${ }^{19}$

Remarkably, despite the published data elsewhere, an examination of EMS calls in the UK shows no delay in seeking help when citizens experience critical symptoms. ${ }^{27}$ However, one cardiac center in England witnessed a significant symptom-to-hospital arrival delay from 3.4 to 13.2 hours during the pandemic. ${ }^{28}$

This recognized disruption to the chain of survival by the pandemic has resulted in a global surge of prehospital mortality. When applied in Italy, mathematical models demonstrate an increase of mortality rates by $300 \%$ one month after the onset of COVID-19. ${ }^{17}$ In India, out-ofhospital mortality surged $45 \%$ in the 15 top hospitals, and to $80 \%$ in seven others between March and April, 2020. ${ }^{30}$ Although not yet confirmed, the excess out-of-hospital mortalities by $145 \%$ in Tijuana, Mexico, documented during the peak of COVID-19 were likely a combination of undetected COVID-19 cases, fatalities secondary to delay of care, and a saturated healthcare system. ${ }^{14}$

In Texas, USA, out-of-hospital-cardiac-arrest (OHCA) cases spiked by $113 \%$ in April 2020, when compared to the previous year, and on-scene pronounced death rate by $164 \%$ during the same period. ${ }^{23}$ In NYC, the death rate climbed to six times above baseline from the onset of COVID-19 through April 2020. ${ }^{31}$ Table 2 summarizes these findings.

Table 2 Call Dispatched to Stroke, Calls Dispatched to Acute Cardiac Illness, Out of Hospital Cardiac Arrests (OHCA), and Out-ofHospital Mortality, During the Peak of Pandemic by City and Country, March to June 2020

\begin{tabular}{|l|l|l|l|l|}
\hline Cityl Country & $\begin{array}{l}\text { Call Dispatched to } \\
\text { Stroke }\end{array}$ & $\begin{array}{l}\text { Calls Dispatched to Acute Cardiac } \\
\text { Illness }\end{array}$ & OHCA & $\begin{array}{l}\text { Out-of-Hospital } \\
\text { Mortality }\end{array}$ \\
\hline Texas, USA & $36 \%$ reduction & $42 \%$ reduction & $\begin{array}{l}\text { II3\% } \\
\text { increase }\end{array}$ & \begin{tabular}{l}
$164 \%$ increase \\
\hline Chicago, USA
\end{tabular} \\
\hline $\begin{array}{l}\text { New Jersey, } \\
\text { USA }\end{array}$ & $29 \%$ reduction & & & \\
\hline NYC, USA & & & & Six times higher \\
\hline $\begin{array}{l}\text { Southern } \\
\text { Europe }\end{array}$ & $25 \%$ reduction & & & \\
\hline Catalonia, Spain & $18 \%$ reduction & & & $45-80 \%$ increase \\
\hline India & & & & $145 \%$ increase \\
\hline Tijuana, Mexico & & & & \\
\hline
\end{tabular}




\section{Total Ambulance Call Time}

Evidence shows a prolonged total ambulance call time during the pandemic. In Italy, an 8-minute ambulance ride took an hour during COVID-19. ${ }^{17}$ Moreover, anecdotal observations indicate reluctance in some trauma centers to receive trauma patients due to the lack of sufficient inpatient capacities ${ }^{28}$ leading to additional travel time.

The new regulations force the donning of appropriate PPE by EMS personnel in preparing for EMS calls, which is considered a time-consuming procedure that impacts the RT of ambulances. ${ }^{33-35}$ Therefore, responding to highacuity trauma patients can be delayed by suiting up with PPE. Paradoxically, a scarcity of PPE and appropriate face masks is found to be a reason in some areas of the world to cause ambulance delays. ${ }^{35}$

\section{Discussion}

\section{EMS Bottleneck Explained}

By exploring the literature, the bottleneck effect resulting from delayed EMS RT during COVID-19 can be attributed to three major factors:

- EMS-related factors

- Social-related factors

- Patient-related factors

The following section will further explain each factor.

\section{EMS-Related Factors}

Four elements were identified under this factor. The first relates to the risk of exposure. One certain fact is the high risk of exposure among EMS personnel to COVID-19, ${ }^{32}$ with a risk of potential staff loss due to contracting the infection. $^{28}$ Indeed, OHCA incidents have increased among COVID-19 patients, prompting the need for the aerosol generating CPR, therefore exposing EMS personnel to an increased risk of exposure. ${ }^{23,33}$

The second element is the shortage of the number of available ambulances, which are not only due to responding to the overwhelming EMS calls, but also to getting ready for the next call. Ambulances have been found to be potential disease vectors. ${ }^{36}$ Therefore, once a vehicle has been exposed to a potentially infectious patient, there is a requirement to decontaminate the ambulance, which will cause further delays and stress on limited EMS resources. $^{37,38}$

The third element of EMS-factors is due to the fact that EMS personnel can be victims of COVID-19 and are subject to death, illness, sick leave and prolonged quarantine, which contribute to staff shortages and further increases the burden on the already strained EMS systems. $^{8,39}$ Although this is not well documented in EMS, it has been witnessed among other health care providers as they are forced to be under quarantine post exposure. $^{40}$

In $\mathrm{NYC}$, a study on fire department personnel documented that, by the end of March 2020, 573 of 4408 EMS clinicians had confirmed cases of COVID-19, and there were 1198 COVID-19 cases among the 11,230 firefighters; ${ }^{41}$ for EMS clinicians the risk was 130 cases per 1000 persons compared to 107 for firefighters; therefore, the relative risk was $20 \%$ higher for EMS personnel than for firefighters. The COVID-related fatality rate has also been higher for EMS personnel compared to other professions. $^{42,43}$

Although EMS personnel regularly face high risks of work-related illness, injury and death, ${ }^{44,45}$ the pandemic also resulted in a risk of EMS personnel crosscontaminating their families. Reports indicate EMS personnel were sleeping in their cars between shifts to prevent that. $^{6,13}$

Finally, although overlooked, is the mental burden on EMS personnel, as there are real concerns about burnout, suicide, ${ }^{46}$ and long-term loss and dropout of EMS personnel due to COVID-19-induced distress. ${ }^{28}$ In NYC, three EMS personnel committed suicide in the first few months of the pandemic. ${ }^{47,48}$

\section{Social-Related Factors}

The main element under this factor is the enforcement of an unprecedented, global lockdown, which has significantly disrupted both EMS' receipt and response to calls. Despite the necessity to reduce COVID-19-related mortalities, ${ }^{17}$ the lockdown has had major unforeseen impacts on attending non-COVID-19 emergencies. Indeed, strict social distancing might be a contributing factor to the frequently undiscovered stroke cases among elderly living alone. ${ }^{24}$ In fact, the negative correlation between lockdown and stroke admissions in Catalonia, Spain, was striking, with zero stroke admissions to a major stroke center during COVID-19 peak days. ${ }^{19}$

Further, the worldwide lockdown has disrupted the global supply chain, including its medical division, resulting in shortage of resources and medical supplies, which significantly affected countries with poor healthcare infrastructures and limited resources. ${ }^{49}$ 


\section{Patient-Related Factors}

The public's behavior towards seeking medical attention also contributes to adverse outcomes. Recent studies conducted in several countries have documented risk-averse behavior among patients during COVID-19. Amid the pandemic, many emergency and non-emergency patients were reluctant to call EMS or seek medical attention, driven by the fear of acquiring the virus. ${ }^{8,14,23,28,49-55}$

The increasing demand on EMSDC by EMS calls seeking inquiries on COVID-19 during the lockdown intensified the bottleneck. This misinterpretation of the role of EMSDC resulted in an unexpected pressure from the public on the only emergency number available.

\section{EMS Strategies to Handle COVID-19}

Several EMSDC strategies have been described to handle COVID-19 pandemic. The most common strategy is dedicating special COVID-19 numbers, ${ }^{7}$ reports show that this has significantly mitigated the enormous demand on the main EMS number. ${ }^{8,12}$ Other effective strategies included screening of potential infections by the EMSDC, a webbased self-triage, increasing EMSDCs capacity for call answering, community paramedics, ${ }^{7,15,39}$ and the development of surge capacity among the response system. ${ }^{56}$ Denmark's EMS Copenhagen has taken several initiatives to tame the immense growth of call volumes, among which is an innovative "Chatbot" to identify COVID-19 related terms. ${ }^{7}$ In France, "the use of seated transport for low acuity cases" proved sufficient in drastically reducing the demand on ambulances. ${ }^{8}$

German paramedicine clinicians helped keep the hospital caseload low during COVID-19 first wave by conducting at-home examinations of low-acuity COVID-19 victims. Regular monitoring allowed clinicians to catch patients before they decompensated and only admitted victims when they required hospitalization. ${ }^{57}$

\section{Conclusion}

At times during the pandemic, EMS calls were mainly for COVID-19 cases, especially in areas hardest hit by the pandemic. Further, it has been observed in many occasions that EMS calls for non-COVID-19 emergencies dropped.

Reportedly, EMS calls will surge dramatically when epidemics is spreading rapidly. Attempting to maintain business as usual at times of crises is not a wise practice, especially with EMS services at its peak. Many EMS models were brisk to adjust their strategies to accommodate the increasing influx of call volumes. The massive influx of call volumes requires EMS systems to revisit their IT and personnel infrastructure, in order to increase their call capacities.

Data from different countries show contradicting evidence in seeking emergency help by victims of critical conditions. This contradiction suggests country-specific behavior that requires further exploration. The findings highlight the need for further research on how EMS call volume may predict hospitalizations, ICU bed demand and deaths in communities.

We need to depart our comfort zones when developing disaster response plans. This research shows EMS agencies' urgent need to share their experiences as case studies in order to support global EMS improvement, inform decision makers and to shape EMS future. If nothing else, this disaster has demonstrated that we live in an interdependent world in which we are more successful when we work together.

\section{Abbreviations}

EMS, emergency medical services; EMT, emergency medical technicians; EMSDC, emergency medical services dispatch center(s); RT, response time; TTR, time-toresponse; COVID-19, 2019 novel coronavirus; PPE, personal protective equipment; NYC, New York City; OHCA, out-of-hospital-cardiac-arrest; CPR, cardiopulmonary resuscitation; AI, artificial intelligence.

\section{Acknowledgments}

Authors would like to acknowledge the Deanship of Graduate Studies and Research (DGSR) at Ajman University, UAE, for supporting in financing "Open Access" fees of this paper.

\section{Disclosure}

Authors confirm no conflict of interest to disclose.

\section{References}

1. Maguire BJ, Phelps S, Maniscalco P, et al. Paramedicine strategic planning. JEMS. 2020. Available from https://www.jems.com/2020/ 05/14/paramedicine-strategic-planning/.

2. Maguire BJ, Dean S, Bissell RA, Walz BJ, Bumbak AK. Epidemic and bioterrorism preparation among emergency medical services systems. Prehosp Disaster Med. 2007;22(3):237-242. doi:10.1017/s1049023x0 000474x

3. Walz B, Bissell R, Maguire B, Judge J. Vaccine administration by paramedics: a model for bioterrorism and disaster response preparation. Prehosp Disaster Med. 2003;18(4):321-326. doi:10.10 17/S1049023X00001278

4. Al Amiry A. Methicillin-resistant Staphylococcus aureus: an occupational health hazard in the prehospital setting. J Acute Dis. 2015;4 (4):274-276. doi:10.1016/j.joad.2015.06.003 
5. Watkins A. N.Y.C.'s 911 system is overwhelmed. 'I'm Terrified,' a paramedic says; 2020: 26. Available from https://www.nytimes.com/ 2020/03/28/nyregion/nyc-coronavirus-ems.html. Accessed August 28, 2021

6. Pilgrim E, O'Brien K, Margolin J, Francis E. EMS on the front lines dealing with 'madness,' sleeping in their cars to avoid infecting their families. ABC News; 2020. Available from: https://abcnews.go.com/ Health/ems-front-lines-dealing-madness-sleeping-cars-avoid/story? $\mathrm{id}=69901930$. Accessed August 28, 2021.

7. Jensen TW, Holgersen MG, Jespersen MS, et al. Strategies to handle increased demand in the COVID-19 crisis a corona telephone hotline and a web-based self-triage system. Eur PMC. 2020;25(1):28-38. doi:10.21203/rs.3.rs-30013/v1

8. Dami F, Berthoz V. Lausanne medical dispatch center's response to COVID-19. Scand J Trauma Resuscit Emerg Med. 2020;28(1):1-3. doi:10.1186/s13049-020-00735-8

9. JBI GLOBAL WIKI. Appendix 11.2 PRISMA ScR extension fillable checklist - JBI manual for evidence synthesis; 2021. Available from https://wiki.jbi. global/display/MANUAL/Appe. Accessed January 15, 2021.

10. Gaubert S, Akian M, Allamigeon X, et al. Understanding and monitoring the evolution of the Covid-19 epidemic from medical emergency calls: the example of the Paris area. HAL; 2020. Id: hal-02648075. Available from: https://hal.inria.fr/hal-02648075v2. Accessed August 28, 2021.

11. den Uil C. Early indicators of intensive care unit bed requirement during the COVID-19 epidemic: a retrospective study in Ile-de-France region, France. By the COVID-19 APHP-Universities-INRIA-INSERM Group. PLoS One. 2020;15(11):e0241406. doi:10.1371/journal.pone.0241406

12. Jaffe E, Strugo R, Bin E, et al. The role of emergency medical services in containing COVID-19. Am J Emerg Med. 2020;38 (7):1526-1527. doi:10.1016/j.ajem.2020.04.023

13. Wang HL. 'I hear the agony': Coronavirus crisis takes toll on nyc's first responders. NPR Choice page; 2020. Available from: https:// www.npr.org/2020/04/23/842011186/i-hear-the-agony-coronaviruscrisis-takes-toll-on-nyc-s-first-responders. Accessed August 28, 2021.

14. Friedman J, Calderón-Villarreal A, Bojorquez I, Vera Hernández C, Schriger D, Tovar Hirashima E. Excess out-of-hospital mortality and declining oxygen saturation: the sentinel role of emergency medical services data in the COVID-19 crisis in Tijuana, Mexico. Ann Emerg Med. 2020;76(4):413-426. doi:10.1016/j.annemergmed.2020.07.035

15. Semeraro F, Gamberini L, Tartaglione M, et al. An integrated response to the impact of coronavirus outbreak on the Emergency Medical Services of Emilia Romagna. Resuscitation. 2020;151:1-2. doi:10.1016/j.resuscitation.2020.03.005

16. Perlini S, Canevari F, Cortesi S, et al. Emergency department and out-ofhospital emergency system (112-AREU 118) integrated response to Coronavirus disease 2019 in a Northern Italy center. Intern Emerg Med. 2020;15(5):825-833. doi:10.1007/s11739-020-02390-4

17. Ciminelli G, Garcia-Mandicó S. Mitigation policies and emergency care management in Europe's ground zero for COVID-19. SSRN Electron J. 2020. doi:10.2139/ssrn.3604688. Available from: https://papers.ssrn. com/sol3/papers.cfm?abstract_id=3604688. Accesse August 31, 2021.

18. Lapostolle F, Agostinucci JM, Alhéritière A, Petrovic T, Adnet F. Collateral consequences of COVID-19 epidemic in Greater Paris. Resuscitation. 2020;151:6-7. doi:10.1016/j.resuscitation.2020.04.010

19. Rudilosso S, Laredo C, Vera V, et al. Acute stroke care is at risk in the era of COVID-19. Stroke. 2020;51(7):1991-1995. doi:10.1161/ STROKEAHA. 120.030329

20. Ganapatye S. Man awaiting ambulance dies, another waits $12 \mathrm{hrs}$. Mumbai Mirror; 2020. Available from: https://mumbaimirror.india times.com/coronavirus/news/man-awaiting-ambulance-dies-anotherwaits-12-hrs/articleshow/75228271.cms. Accessed August 28, 2021.

21. Singh L, Barnagarwala T. Delay in ambulance services continue, wait time several hours in Mumbai. The Indian Express; 2020. Available from: https://indianexpress.com/article/cities/mumbai/delay-inambulance-services-continue-wait-time-several-hours-in-mumbai -6400813/. Accessed August 28, 2021.
22. Spinney L. Concern as heart attack and stroke patients delay seeking help. The Guardian; 2020. Available from: https://www.theguardian. com/world/2020/apr/16/coronavirus-concern-heart-attack-strokepatients-delay-seeking-help. Accessed August 28, 2021.

23. Zavadsky M. Complete April data shows alarming 911 trends for EMS calls during the COVID-19 pandemic. JEMS. 2020. Available from https://www.jems.com/2020/05/05/calls-during-the-covid-19-pandemic/.

24. Dafer R, Osteraas N, Biller J. Acute stroke care in the Coronavirus disease 2019 pandemic. J Stroke Cerebrovasc Dis. 2020;29 (7):104881. doi:10.1016/j.jstrokecerebrovasdis.2020.104881

25. Siegler J, Heslin M, Thau L, Smith A, Jovin T. Falling stroke rates during COVID-19 pandemic at a comprehensive stroke center. J Stroke Cerebrovasc Dis. 2020;29(8):104953. doi:10.1016/j. jstrokecerebrovasdis.2020.104953

26. Montaner J, Barragán-Prieto A, Pérez-Sánchez S, et al. Break in the stroke chain of survival due to COVID-19. Stroke. 2020;51:23 07-2314. doi:10.1161/strokeaha.120.030106

27. Holmes JL, Brake S, Docherty M, Lilford R, Watson S. Emergency ambulance services for heart attack and stroke during UK's COVID-19 lockdown. Lancet. 2020;395(10237):e93-e94. doi:10.1016/s01406736(20)31031-x

28. Abdelaziz HK, Abdelrahman A, Nabi A, et al. Impact of COVID-19 pandemic on patients with ST-segment elevation myocardial infarction: insights from a British cardiac center. Am Heart J. 2020;226:45-48. doi:10.1016/j.ahj.2020.04.022

29. Haut E, Leeds I, Livingston D. The effect on trauma care secondary to the COVID-19 pandemic: collateral damage from diversion of resources. Ann Surg. 2020;272:e204-e207. doi:10.1097/SLA.00000 00000004105

30. Garari K. Here's how ambulance difficulties are killing non-Covid-19 patients. Deccan Chronicle; 2020. Available from: https:/www.dec canchronicle.com/nation/in-other-news/010520/heres-howambulance-difficulties-are-killing-non-covid-19-patients.html. Accessed August 28, 2021.

31. Katz J, Sanger-Katz M. N.Y.C. deaths reach 6 times the normal level, far more than coronavirus count suggests. New York Times Web; 2020. Available from: https://www.nytimes.com/interactive/2020/04/27/ upshot/coronavirus-deaths-new-york-city.html. Accessed August 28, 2021.

32. Murphy DL, Barnard LM, Drucker CJ, et al. Occupational exposures and programmatic response to COVID-19 pandemic: an emergency medical services experience. Emerg Med J. 2020;37:707-713. doi:10.1136/emermed-2020-210095

33. Mahmud E, Dauerman H, Welt F, et al. Management of acute myocardial infarction during the COVID-19 pandemic. $\mathrm{J}$ Am Coll Cardiol. 2020;76(11):1375-1384. doi:10.1016/j.jacc.2020.04.039

34. Whitfield S, MacQuarrie A, Boyle M. Responding to a cardiac arrest: keeping paramedics safe during the COVID-19 pandemic. Austral $J$ Paramed. 2020;17. doi:10.33151/ajp.17.809. Available from: https://ajp.paramedics.org/index.php/ajp/article/view/809. Accessed August 31, 2021.

35. Ehrlich H, McKenney M, Elkbuli A. Defending the front lines during the COVID-19 pandemic: protecting our first responders and emergency medical service personnel. Am J Emerg Med. 2020;40: 213-214. doi:10.1016/j.ajem.2020.05.068

36. Makiela S, Taylor-Robinson AW, Weber A, Maguire BJ. A preliminary assessment of contamination of emergency service helicopters with MRSA and multi-resistant Staphylococcus aureus. Emerg Med. 2016;6:304.[0.25]. doi:10.4172/2165-7548.1000304

37. Avery J, Bloom B. COVID-19, a UK perspective. Eur J Emerg Med. 2020;27(3):156-157. doi:10.1097/MEJ.0000000000000700

38. Temporary emergency guidance to STEMI systems of care during the COVID-19 pandemic. Circulation. 2021;142:199-202. doi:10.1161/ CIRCULATIONAHA.120.048180. Available from: https://www.aha journals.org/doi/10.1161/CIRCULATIONAHA.120.048180. Accessed August 31, 2021. 
39. Hick J, Hanfling D, Wynia M, Pavia A. Duty to plan: health care, crisis standards of care, and Novel Coronavirus SARS-CoV-2. Natl Acad Med. 2020. doi:10.31478/202003b Available from: https://nam. edu/duty-to-plan-health-care-crisis-standards-of-care-and-novel-coro navirus-sars-cov-2/. Accessed August 31, 2021.

40. Arnold RH, Tideman PA, Devlin GP, et al. Rural and remote cardiology during the COVID-19 pandemic: Cardiac Society of Australia and New Zealand (CSANZ) consensus statement. Heart Lung Circ. 2020;29(7): e88-e93. doi:10.1016/j.hlc.2020.05.001

41. Prezant D, Zeig-Owens R, Schwartz T, et al. Medical leave associated with COVID-19 among emergency medical system responders and firefighters in New York City. JAMA Netw Open. 2020;3(7): e2016094. doi:10.1001/jamanetworkopen.2020.16094

42. Maguire BJ, O’Neill BJ, Gerard DR, Maniscalco PM, Phelps S, Handal KA. Occupational fatalities among EMS clinicians and firefighters in the New York City fire department; January to August 2020. JEMS. 2020. Available from https://www.jems.com/corona virus/occupational-fatalities-among-ems-clinicians-and-firefighters/.

43. Maguire BJ, O’Neill BJ, Phelps S, Maniscalco PM, Gerard DR, Handal KA. COVID-19 fatalities among EMS clinicians. EMS1. 2020. Avaiblable from: https://www.ems1.com/ems-products/perso nal-protective-equipment-ppe/articles/covid-19-fatalities-among-emsclinicians-BMzHbuegIn1xNLrP/. Accessed August 31, 2021.

44. Maguire BJ, O’Meara PF, Brightwell RF, O’Neill BJ, Fitzgerald GJ. Occupational injury risk among Australian paramedics: an analysis of national data. Med J Aust. 2014;200(8):477-480. doi:10.5694/mja13. 10941

45. Maguire BJ, Smith S. Injuries and fatalities among emergency medical technicians and paramedics in the United States. Prehosp Disaster Med. 2013;28:376-382. doi:10.1017/s1049023x13003555

46. Ortega R. NYC EMT, 23, commits suicide after working COVID-19 hotspots. Mail Online; 2020. Available from: https://www.dailymail.co. uk/news/article-8258519/New-York-City-EMT-23-commits-suicidethree-months-job-working-COVID-19-hotspots.html. Accessed August 28, 2021.

47. Moynihan E, Otis GA, Burke K, Tracy T. 'He was an amazing son': off-duty FDNY EMS lieutenant takes his own life, second EMS suicide this year. NY Daily News; 2020. Available from: https:// www.nydailynews.com/new-york/nyc-crime/ny-off-duty-fdny-emslieutenant-suicide-20200620-f5vmh3sdobemrcrtzo5uwqffty-story. html. Accessed August 28, 2021.
48. Barone V, Edelman S. Off-duty FDNY EMT commits suicide, the third to take their life this year. New York Post; 2020. Available from https://nypost.com/2020/07/17/off-duty-fdny-emt-commits-suicide/\#: :text=An\%20off\%2Dduty\%20FDNY\%. Accessed August 28, 2021.

49. Pramesh CS, Badwe RA. Cancer management in India during Covid-19. N Engl J Med. 2020;382(20):e61-e61. doi:10.1056/NEJMc2011595

50. Pata D, Gatto A, Buonsenso D, et al. A COVID-19 outbreak's lesson: best use of the paediatric emergency department. Acta Paediatr. 2020;109(9):1903-1904. doi:10.1111/apa.15386

51. Wong L, Hawkins J, Langness S, Murrell K, Iris P, Sammann A. Where are all the patients? Addressing Covid-19 fear to encourage sick patients to seek emergency care | catalyst non-issue content. NEJM Catal Innov Care Deliver. 2020. doi:10.1056/CAT.20.0193. Available from: https://catalyst.nejm.org/doi/full/10.1056/CAT.20. 0193. Accessed August 31, 2021.

52. Lazzerini M, Barbi E, Apicella A, Marchetti F, Cardinale F, Trobia G. Delayed access or provision of care in Italy resulting from fear of COVID-19. Lancet Child Adolesc Health. 2020;4(5):e10-e11. doi:10.1016/s2352-4642(20)30108-5

53. Mosley M. News: did diseases freeze during the COVID-19 surge? Emerg Med News. 2020;2(6C):10-97. doi:10.1097/01.eem.0000677392.96162. b9

54. Mareiniss D. The impending storm: COVID-19, pandemics and our overwhelmed emergency departments. Am J Emerg Med. 2020;38 (6):1293-1294. doi:10.1016/j.ajem.2020.03.033

55. Roffi M, Guagliumi G, Ibanez B. The obstacle course of reperfusion for ST-segment-elevation myocardial infarction in the COVID-19 pandemic. AHA Circulation. 2020;141:1951-1953. doi:10.1161/ CIRCULATIONAHA.120.047523

56. Tien H, Sawadsky B, Lewell M, Peddle M, Durham W. Critical care transport in the time of COVID-19. CJEM. 2020;13:1-5. doi:10. 1017/cem.2020.400

57. Benhold K. A German exception? Why the country's Coronavirus death rate is low. The New York Times. 2020. Available from https:// www.nytimes.com/2020/04/04/world/europe/germany-coronavirusdeath-rate.html. Accessed August 28, 2021.
Open Access Emergency Medicine

\section{Publish your work in this journal}

The Open Access Emergency Medicine is an international, peerreviewed, open access journal publishing original research, reports, editorials, reviews and commentaries on all aspects of emergency medicine. The manuscript management system is completely online and includes a very quick and fair peer-review system, which is all easy to use. Visit http://www.dovepress.com/testimonials.php to read real quotes from published authors. 